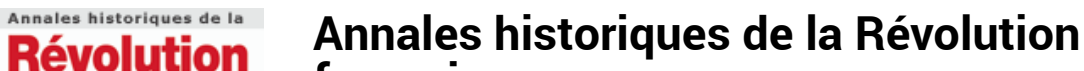

française française

317 | juillet-septembre 1999

Numéro spécial : France-Allemagne. Interactions,

références

\section{Hommage à Michel Peronnet (1931-1998)}

\section{Geneviève Gavignaud-Fontaine}

\section{(2) OpenEdition \\ 1 Journals}

Édition électronique

URL : https://journals.openedition.org/ahrf/1986

DOI : 10.4000/ahrf.1986

ISSN : 1952-403X

Éditeur :

Armand Colin, Société des études robespierristes

\section{Édition imprimée}

Date de publication : 1 septembre 1999

Pagination : $567-568$

ISSN : 0003-4436

\section{Référence électronique}

Geneviève Gavignaud-Fontaine, « Hommage à Michel Peronnet (1931-1998) », Annales historiques de la Révolution française [En ligne], 317 | juillet-septembre 1999, mis en ligne le 11 avril 2006, consulté le 23 avril 2022. URL : http://journals.openedition.org/ahrf/1986 ; DOI : https://doi.org/10.4000/ahrf.1986

Ce document a été généré automatiquement le 23 avril 2022.

Tous droits réservés 


\title{
Hommage à Michel Peronnet (1931-1998)
}

\author{
Geneviève Gavignaud-Fontaine
}

1 La Commission régionale d'Histoire de la Révolution française Languedoc-Roussillon a perdu son Président-fondateur. Professeur à l'Université de Montpellier, Michel Péronnet avait institutionnalisé, dès 1984-1985, la préparation du Bicentenaire de la Révolution de 1789, dans la mouvance de la réputée Commission nationale, fort active depuis son siège parisien, sous l'autorité de Michel Vovelle.

2 Par cette décision, le Président Péronnet avait engagé une équipe dont il avait pris la tête avec enthousiasme, dans de massifs projets qui devaient s'étaler sur dix années de commémoration, eu égard aux événements de 1789-1799. Ce faisant, Michel Péronnet resserrait ses liens avec ses collègues de la Sorbonne où il avait été successivement assistant et maître-assistant (1969-1971) ; il renforçait ainsi son intérêt pour l'analyse de la période révolutionnaire, intérêt précédemment développé au contact d'Albert Soboul.

3 À Montpellier, le Professeur Péronnet ajouta cette spécialisation dans les études révolutionnaires à la spécialisation en histoire religieuse que lui avait conférée sa thèse de doctorat d'État ( les Évêques de l'Ancienne France, 1978). Sa remarquable capacité de travail lui permit de maintenir deux fers au feu : le Centre d'Histoire des Réformes et du Protestantisme et la Commission d'Histoire Régionale de la Révolution Française. Le premier était hérité de Jean Boisset, la seconde prenait le relais des efforts déployés par Robert Laurent pour stimuler la recherche sur les événements de la Révolution.

Entraînant dans son sillage collègues, chercheurs, étudiants liés aux Universités de Montpellier, Perpignan, et même Toulouse, Michel Péronnet a orchestré et dirigé, pendant une quinzaine d'années, de nombreuses rencontres sur l'histoire de la période révolutionnaire. Il a œuvré, en liaison avec les équipes de Barcelone et de Florence, pour préparer un congrès sur Les Jacobins du Midi; il s'est allié à la Faculté de Médecine de Montpellier, pour consacrer à Chaptal un colloque et un ouvrage.

5 À ces travaux d'équipe, Michel Péronnet a joint des publications personnelles: une introduction à l'Histoire Départementale de la Révolution Française, aux éditions Horvath ; 
une étude des mots clés des événements et de leur époque, aux éditions Privat. Inlassablement toujours, et avec fougue souvent, il a participé à la plupart des rencontres organisées autour du Bicentenaire, en province, à Paris, en Amérique. La longue série d'interventions et de publications, venue prestigieusement renforcer la liste de ses travaux, témoigne de la variété des thèmes abordés et de l'intensité du rythme soutenu. La vocation d'historien de Michel Péronnet trouvait là sa mesure et son épanouissement.

6 Lorsque la maladie lança ses premiers assauts, le Professeur poursuivit imperturbablement ses activités de recherche et d'enseignement. Quelques jours avant de mourir, il avait adressé à ses collègues une invitation - pressante - à participer aux futures rencontres dont il avait en charge l'organisation. Ses collègues auront à cœur de tenir les engagements pris. 